\title{
Omega-3-Acid Ethyl Esters
}

National Cancer Institute

\section{Source}

National Cancer Institute. Omega-3-Acid Ethyl Esters. NCI Thesaurus. Code C66255.

An ethyl ester form of omega-3 fatty acid derived from fish oil, with activity in decreasing serum triglyceride levels. Although its mechanism of action isn't known, omega-3-acid ethyl esters may work by decreasing the amount of triglycerides and other fats made in the liver. 